\title{
Rate and Severity of HIV-Associated Dementia (HAD): Correlations with Gp41 and iNOS
}

\author{
D. Cory Adamson, ${ }^{1,2}$ Justin C. McArthur, ${ }^{1,4}$ Ted M. Dawson, ${ }^{1,2}$ \\ and Valina L. Dawson ${ }^{1,2,3}$ \\ Departments of ${ }^{1}$ Neurology, ${ }^{2}$ Neuroscience, and ${ }^{3}$ Physiology, Johns \\ Hopkins University School of Medicine, Baltimore, Maryland, U.S.A. \\ ${ }^{4}$ Department of Epidemiology, Johns Hopkins University School of \\ Hygiene and Public Health, Baltimore, Maryland, U.S.A.
}

Communicated by S. Snyder. Accepted January 25, 1999.

\begin{abstract}
Background: Fifteen to thirty percent of AIDS patients develop some type of neurologic disorder during the course of their illness and the vast majority of these neurologic disorders will be HIV-associated dementia (HAD). These patients can exhibit varying degrees of severity and rates of progression of HAD. Neuropathologic variables that are associated with the rate of progression of HAD are not known.

Materials and Methods: Tissue was collected at autopsy from the Johns Hopkins University HIV Neurology Program. Seventy-one AIDS patients of this prospectively characterized population were followed until death to obtain information on dementia severity and the rate of neurological progression. Immunoblot analysis of immunological nitric oxide synthase (iNOS), HAM56, gp41, p24, gp120, and $\beta$-tubulin was performed and the levels of iNOS, HAM56, gp41, and p24 were normalized to $\beta$-tubulin and analyzed for significance by means of the Kruskal-Wallis test for multiple groups.
\end{abstract}

Results: We have identified unique groups within this spectrum and designated them slow, moderate, and rapid progressors. Slow and moderate progressors' neurological progression occurs over a course of months to years, whereas the rapid progressors' disease shows rapid increases in severity over weeks to months. In the present study we demonstrate that the severity and rate of progression of $\mathrm{HAD}$ correlates significantly with levels of the HIV-1 coat protein, gp41, iNOS, and HAM56, a marker of microglial/macrophage activation.

Conclusion: The severity and rate of progression of $\mathrm{HAD}$ correlates with indices of immune activation as well as levels of iNOS and gp4l. There appears to be a threshold effect in which high levels of gp4l, iNOS, and immune activation are particularly associated with severe (Memorial Sloan-Kettering score 3 to 4 ) and rapidly progressive $\mathrm{HAD}$.

\section{Introduction}

Fifteen to thirty percent of AIDS patients have neurologic disorders such as HIV-associated dementia (HAD), minor cognitive/motor disorder, HIV-associated myelopathy, and HIV-associated sensory neuropathy (1). These are among the

Address correspondence and reprint requests to: Dr. Valina L. Dawson, Johns Hopkins Hospital, 600 N. Wolfe St., Carnegie 214, Baltimore, MD 21287, U.S.A. Phone: 410-6143361; Fax: 410-614-9568; E-mail: vdawson@jhmi.edu most common causes of neurologic disease in young adults in the United States today (1). HAD has an overall prevalence among HIV-infected children and adults of 15 to $20 \%$, and an annual incidence in patients with AIDS of 5 to $10 \%$ (1). Twenty to thirty percent of AIDS patients will develop HAD during the course of their illness (2-4) and higher incidences have been reported in intravenous drug users and women (1).

$$
\text { Human immunodeficiency virus type-1 }
$$


(HIV-1) preferentially infects $\mathrm{CD} 4^{+}$cells of the peripheral immune system and it also targets $\mathrm{CD} 4^{+}$ immune cells of the central nervous system, primarily microglia and perivascular macrophages, early in the course of HIV-1 infection $(5,6)$. Despite the occasional infection of astrocytes and the rare infection of neurons (7-10), there is cortical neuronal and synaptic loss and dendritic simplification (11-13). Therefore, indirect mechanisms are most likely to be involved in the pathogenesis of $\mathrm{HAD}$ $(14,15)$. Neuropathologic studies indicate that HAD may be related to levels of unintegrated viral DNA, multinucleated giant cells, positive immunostaining for gp4l and p24 (16), and immunostaining for a unique subset of apoptotic-inducing CD 14/CD16positive and CD14/CD69-positive monocytes (17). Psychomotor slowing as well as increased levels of cerebrospinal fluid (CSF) $\beta 2$-microglobulin and neopterin and decreased CD4 counts (18) carry an increased risk of progression to dementia (19).

The severity of HAD may also correlate with the number of HIV-1-infected macrophages $(5,20-22)$, and CSF RNA viral burden (23). Recently we showed that levels of gp4l as ascertained by Western blot analysis correlate with the severity of HAD and the levels of immunological nitric oxide synthase (iNOS) (24). Gp4l is also increased in pediatric patients with progressive neurologic disease (25). In SIV-infected macaques, neurologic disease correlates with gp4l expression, but not with viral load as detected by viral message (J. Clement and M. C. Zink, personal communication), paralleling observations made in HAD. Expression of mRNA for iNOS, tumor necrosis factor- $\alpha$ (TNF- $\alpha$ ), and macrophage inflammatory protein $\alpha$ (MIP-1 $\alpha$ ) and $\beta$ $(\mathrm{MIP}-1 \beta)$ is in close proximity to gp4l-positive cells in HAD patients (26). MIP- $1 \alpha$ and MIP- $1 \beta$ are potent chemoattractants for both monocytes and specific subpopulations of lymphocytes. In rodent neuronal/glial and human neuronal aggregate cultures, physiologic subnanomolar concentrations of gp4l induce a cascade of events that is neurotoxic by inducing iNOS- and nitric oxide (NO)-dependent neurotoxicity (24; L. Pulliam, personal communication). Thus, in addition to other viral proteins and host factors, gp4l may play a key role in the pathogenesis of HAD.

The rate of progression of HIV infection to AIDS is influenced by factors including older age $(27,28)$, lower $\mathrm{CD} 4^{+}$cell count $(27)$, decreased hemoglobin, reduced platelet count, and elevated IgA levels and thrush (29); however, disease progression is not associated with race, sex, or risk factor for HIV infection (30). Variations in viral genotype, production by infected macrophages, and subsequent toxin production may contribute to the variability in neuropathology (31) and likewise the variability in neurological progression of HAD. Many studies describing characteristics of HAD looked primarily at cases of rapid progression over a few months, with a mean survival of 3 to 6 months (32-35); few have given attention to differences among variable rates of progression of HAD (36) in relation to neuropathologic correlates. We report here that the severity and rate of progression of HAD correlate with levels of gp4l and iNOS.

\section{Patients and Methods}

\section{Study Subjects}

Using the American Academy of Neurology (AAN) criteria (37) (equivalent criteria for cases before 1991), the Johns Hopkins University HIV Neurology Program diagnosed 329 adult patients with HAD between 1984 and 1994. Seventy-one of these patients were followed until death to obtain information on dementia severity and rate of neurological progression. All of these patients received neurological or neuropsychological examinations within 3 months of death, had a follow-up of $>1$ month, and had initial Memorial Sloan-Kettering (MSK) scores (38) of $<3$. None of these patients had clinical or pathological evidence of pre-existing or concurrent central nervous system (CNS) opportunistic infections, confounding illicit drug use, or pre-existing psychiatric disorders.

Rate of neurological progression was ascertained according to the change in the MSK dementia severity score (38) at initial diagnosis and at death. The criteria for classification of progression rates are described by Bouwman and colleagues (36) in detail and for purposes of brevity are not repeated here. On the basis of these calculated rates of dementia progression, the group was divided into tertiles and compared according to demographic, clinical, and laboratory characteristics. For this study, 11 of these patients were randomly selected, along with HIV-positive, nondemented individuals, for protein analysis of postmortem CNS tissue. The nondemented, slow, moderate, and rapid progression groups each had eight, three, four, and four individuals, respectively. For purposes of statistical power and further assessment of neuropathologic variables associated with severity of dementia, we also combined these immunoblot results 
with previous findings (24) and examined potential correlations with severity of dementia at time of death. For this analysis, we had a total of 26 samples from individuals with MSK scores at time of death ranging from 0 to 4 .

\section{Demographic and Clinical Data}

Baseline demographic information included age, survival from time of HAD diagnosis, $\mathrm{CD} 4$ count near time of death, and postmortem interval (time from death to fixation or freezing of CNS tissue). Other demographic and clinical data collected included race, sex, risk factor for HIV infection (homo- or bisexual, heterosexual, injection drug use, blood transfusion, or unknown), antiretroviral use, AIDS-defining illnesses, radiological results, presenting signs and symptoms, clinical staging of HIV disease, results from neuropsychological testing including Mini Mental State Exam scores (39) or HIV-dementia scale (40), as well as a complete neurological history. These other data are reported in detail elsewhere (36) and are not repeated here.

\section{Immunoblot Analysis}

Tissue was collected at autopsy from this prospectively characterized population of AIDS patients, was rapidly frozen in isopentane, and stored at $-70^{\circ} \mathrm{C}$. Cortical specimens were obtained from the mid-frontal gyrus from all patients. In all patients, the presence of CNS opportunistic infections or lymphoma was excluded by computed tomography (CT) or magnetic resonance imaging (MRI) and CSF analysis, as well as by postmortem histopathologic evaluation of brain tissue sections. HIV-1-seronegative control specimens were obtained from patients without CNS lesions and have been previously reported (24). The causes of death in control patients included myocardial infarction, trauma, cirrhosis of the liver, atherosclerosis, and widespread cytomegalovirus infection.

Immunoblot analysis of iNOS, HAM56, gp4l, p24, gp120, and $\beta$-tubulin was performed as described previously (24). Briefly, tissues were homogenized in ice-cold $50 \mathrm{mM}$ Hepes ( $\mathrm{pH} 7.4$ ) with $1 \mathrm{mM} \beta$-mercaptoethanol, $1 \mathrm{mM}$ phenylmethylsulfonyl fluoride, $1 \mathrm{mM}$ benzamide, leupeptin $(10 \mu \mathrm{g} / \mathrm{ml})$, pepstatin $\mathrm{A}(10 \mu \mathrm{g} / \mathrm{ml})$, aprotinin $(1 \mu \mathrm{g} / \mathrm{ml})$, and $1 \mathrm{mM}$ EDTA, and centrifuged at $100,000 \times g$ for $60 \mathrm{~min}$. Five to sixteen percent gradient polyacrylamide gel electrophoresis (PAGE) was used to separate pro- teins. After electrophoresis, proteins were electroblotted onto nitrocellulose and incubated with anti-macNOS antibody (1:500, Transduction Laboratories, Lexington, $\mathrm{KY}$ ), anti-macrophage "HAM56" antibody (1:1000, Enzo Diagnostics, Farmingdale, NY), anti-gp41 antibody (1:250, \#1577, Intracel, Cambridge, MA), anti-p24 (HIV-1) antibody (1:1000, Intracel), anti-gp120 (HIV-1) antibody (1:250, Intracel), and anti- $\beta$ tubulin antibody $(1: 10000$, Sigma Immuno Chemicals, St. Louis, MO), respectively. The anti-gp4l antibody is epitope mapped to gp4l amino acids 733-750 and recognizes only one protein that runs at $41 \mathrm{kD}$ only in HIV-infected patients (24). We have never detected immunoreactivity by Western blot analysis in HIV-seronegative controls. Furthermore, the gp4l epitope (aa 733-750) does not have any significant homology to any currently known human proteins as determined by both BLAST and BLITZ protein sequence searches. The anti-gpl 20 antibody recognizes recombinant gpl20 and native gp120 from extracts of HIV-1-infected cells in Western blots (24). For gp4l protein analysis, equivalent amounts of protein lysate prepared from each of the pellet fractions after a $60-$ min $100,000 \times g$ spin were resolved using $4-20 \%$ gradient PAGE. Sodium dodecyl sulphate $(0.1 \%)$ was added to the Tris-glycine buffer and Tween $20(0.1 \%)$ was added to the phosphate-buffered saline (PBS) for rinsing steps. Immunoblots were developed by enhanced chemoluminescence (Kirkegaard \& Perry Laboratories, Gaithersburg, MD). Bands were scanned (Molecular Dynamics, Sunnyvale, CA) and relative ratios of the intensity of the bands to the $\beta$-tubulin band were calculated.

\section{Statistical and Correlation Data}

The levels of iNOS, HAM56, gp41, and p24 normalized to $\beta$-tubulin were analyzed for significance by means of the Kruskal-Wallis test for multiple groups. Data are reported here as means \pm SEM. Fisher's least-significance difference posthoc test was used for each protein and comparison of significance was made between each neurological progression group and MSK scores. Protein level versus rate of neurological progression, and protein levels versus MSK score scattergram plots were generated by a bivariate regression analysis program. Nonparametric Spearman rank correlation tests were used to compare protein levels with rate of neurological progression and with MSK score at time of death. 


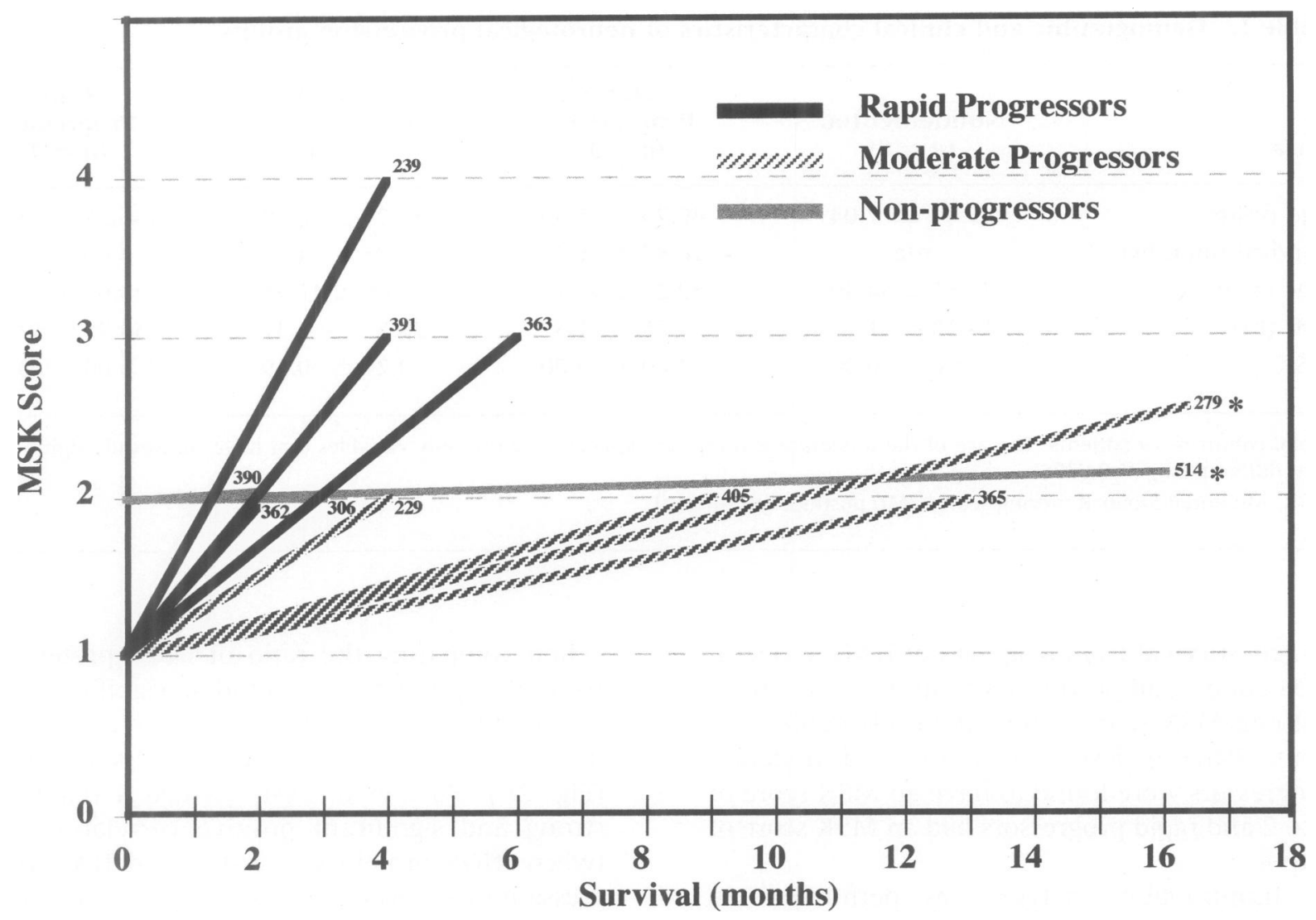

Fig. 1. Different rates of neurological progression among non-progressors (NP), moderate progressors (MP), and rapid progressors (RP). Seropositive nondemented cases are not shown since they have no survival value. The mean Memorial Sloan-Kettering (MSK) slope of the NP, MP, and RP groups was 0.000747 ( \pm 0.000606$), 0.00461$

\section{Results}

After selecting a group of patients from the original 71 patients, we divided the group into three on the basis of the rate of change in their MSK score from time of diagnosis to near or at the time of death. The mean MSK slope values for these groups were $0.000747( \pm 0.000606), 0.00461( \pm 0.00156)$, and $0.016842( \pm 0.003286)$, respectively (Fig. 1), and the median MSK slope values were 0.000557, 0.00349 , and 0.01608 , respectively. We designated these groups non-progressors, moderate progressors, and rapid progressors (non-progressors and moderate progressors, $p \leq 0.0064$; non-progressors and rapid progressors, $p \leq 0.0109$; moderate progressors and rapid progressors, $p \leq 0.005$ ). Some of the moderate and rapid progressors had slightly lower MSK scores than the non-progressors. In our analysis of HAD patients with different rates of progression we included a group of HIV-positive
$( \pm 0.00156)$, and $0.016842( \pm 0.003286)$, respectively. The median MSK slope of each group was $0.000557,0.00349$, and 0.01608 , respectively (NP and MP, $p \leq 0.0064$; NP and RP, $p \leq 0.0109$; MP and RP, $p \leq 0.005)$ ). *Survival for case 279 and 514 was 21 and 59.2 months, respectively.

individuals who remained free of $\mathrm{HAD}$ during their lifetime. There was no significant difference among groups with regard to age at the time of death except between moderate progressors and rapid progressors (Table 1). These latter two groups had mean ages of $37.25 \pm 0.99$ and $46.25 \pm 3.84$, respectively ( $p \leq 0.0396$ ). There were no significant differences with regard to length of survival from time of diagnosis of $\mathrm{HAD}$ to death among the groups. There were also no significant differences regarding CD4 counts and postmortem interval.

For purposes of statistical power and further assessment of variables associated with severity of dementia, we combined these immunoblot results with previous findings (24) and divided the combined results into three groups on the basis of MSK score at time of death (Table 2). These groups consisted of MSK scores of 0,1 to 2, and 3 to 4 , and showed no significant difference 
Table 1. Demographic and clinical characteristics of neurological progression groups ${ }^{a}$

\begin{tabular}{lccrr}
\hline Data & $\begin{array}{c}\text { Nondemented } \\
(\boldsymbol{n}=\mathbf{8})\end{array}$ & $\begin{array}{c}\text { Non- } \\
\text { Progressors } \\
(\boldsymbol{n}=\mathbf{3})\end{array}$ & $\begin{array}{c}\text { Moderate } \\
\text { Progressors } \\
(\boldsymbol{n}=\mathbf{4})\end{array}$ & $\begin{array}{c}\text { Rapid } \\
\text { Progressors } \\
(\boldsymbol{n}=\mathbf{4})\end{array}$ \\
\hline Age (years) & $45.00 \pm 7.04$ & $40.75 \pm 5.50$ & $37.25 \pm 0.99$ & $46.25 \pm 3.84$ \\
Survival (months) & $\mathrm{n} / \mathrm{a}$ & $16.80 \pm 28.27$ & $11.75 \pm 4.15$ & $4.00 \pm 0.94$ \\
CD4 count & $76.67 \pm 54.89$ & $50.25 \pm 55.17$ & $77.00 \pm 47.38$ & $23.00 \pm 13.47$ \\
PMI (hr) & $14.38 \pm 1.79$ & $7.75 \pm 1.5$ & $20.5 \pm 6.37$ & $54.75 \pm 52.12$ \\
MSK & $0.00 \pm 0.00$ & $2.00 \pm 0.00$ & $2.25 \pm 0.29$ & $3.00 \pm 0.47$
\end{tabular}

${ }^{a}$ Total cohort $=19$ patients. The age of the moderate and rapid progressors are the only variables that have statistically significant differences. $p \leq 0.0396$.

MSK, Memorial Sloan-Kettering score; PMI, postmortem interval.

in age, survival from diagnosis of HAD to death, CD4 count, and postmortem interval. The group with an MSK score of 0 were nondemented patients. Patients described as non- and moderate progressors were found to have an MSK score of 1 to 2 and rapid progressors had an MSK score of 3 to 4 .

Immunoblot analysis was performed on samples from eight HIV-positive nondemented patient samples, three non-progressors, four moderate progressors, and four rapid progressors. High levels of iNOS protein expression were observed in all rapid progressor samples, in half of the moderate progressors, and at an extremely low level in one of the eight nondemented patients (Fig. 2A). To control for different amounts of protein loaded in each lane of the immunoblot, we also probed the same immunoblots for the ubiquitously expressed $\beta$-tubulin protein.
When comparing the ratio of iNOS protein to $\beta$-tubulin protein, we found a significant increase in the amount of iNOS protein expression in the moderate and rapid progressor groups (Fig. 2B). Further analysis yielded a relatively strong and significant positive correlation between iNOS protein expression and HAD progression $(\rho=0.611, p \leq 0.010$; Fig. $2 \mathrm{C})$. We next evaluated iNOS/ $\beta$-tubulin ratios with MSK scores and combined these data with our previous patient cohort (24). We confirmed and strengthened our original observations, which showed a significant correlation between iNOS protein expression and the severity of HAD as measured by MSK scores $(\rho=0.618, p \leq 0.001$; Fig. 2D).

The relative level or extent of macrophage or microglial activation was assessed by Western blot analysis of HAM56, a marker that is widely

Table 2. Demographic and clinical characteristics of dementia severity groups ${ }^{a}$

\begin{tabular}{lccr}
\hline Data & $\begin{array}{c}\text { MSK 0 } \\
(n=13)\end{array}$ & $\begin{array}{c}\text { MSK 1-2 } \\
(n=11)\end{array}$ & $\begin{array}{c}\text { MSK 3-4 } \\
(n=6)\end{array}$ \\
\hline Age (years) & $46.33 \pm 7.11$ & $41.73 \pm 2.28$ & $43.60 \pm 4.09$ \\
Survival (months) & n/a & $10.11 \pm 7.50$ & $7.32 \pm 4.18$ \\
CD4 count & $80.25 \pm 38.14$ & $40.60 \pm 15.44$ & $44.40 \pm 29.04$ \\
PMI (hr) & $13.54 \pm 1.31$ & $15.09 \pm 3.15$ & $42.83 \pm 32.42$ \\
Progression & ND & NP \& MP & RP \\
\hline
\end{tabular}

${ }^{a}$ Total cohort $=30$ patients. None of the variables are statistically different at $p \leq 0.05$. MP, moderate progression; MSK, Memorial Sloan-Kettering score; ND, no dementia; PMI, postmortem interval; RP, rapid progression; NP, non-progression. 

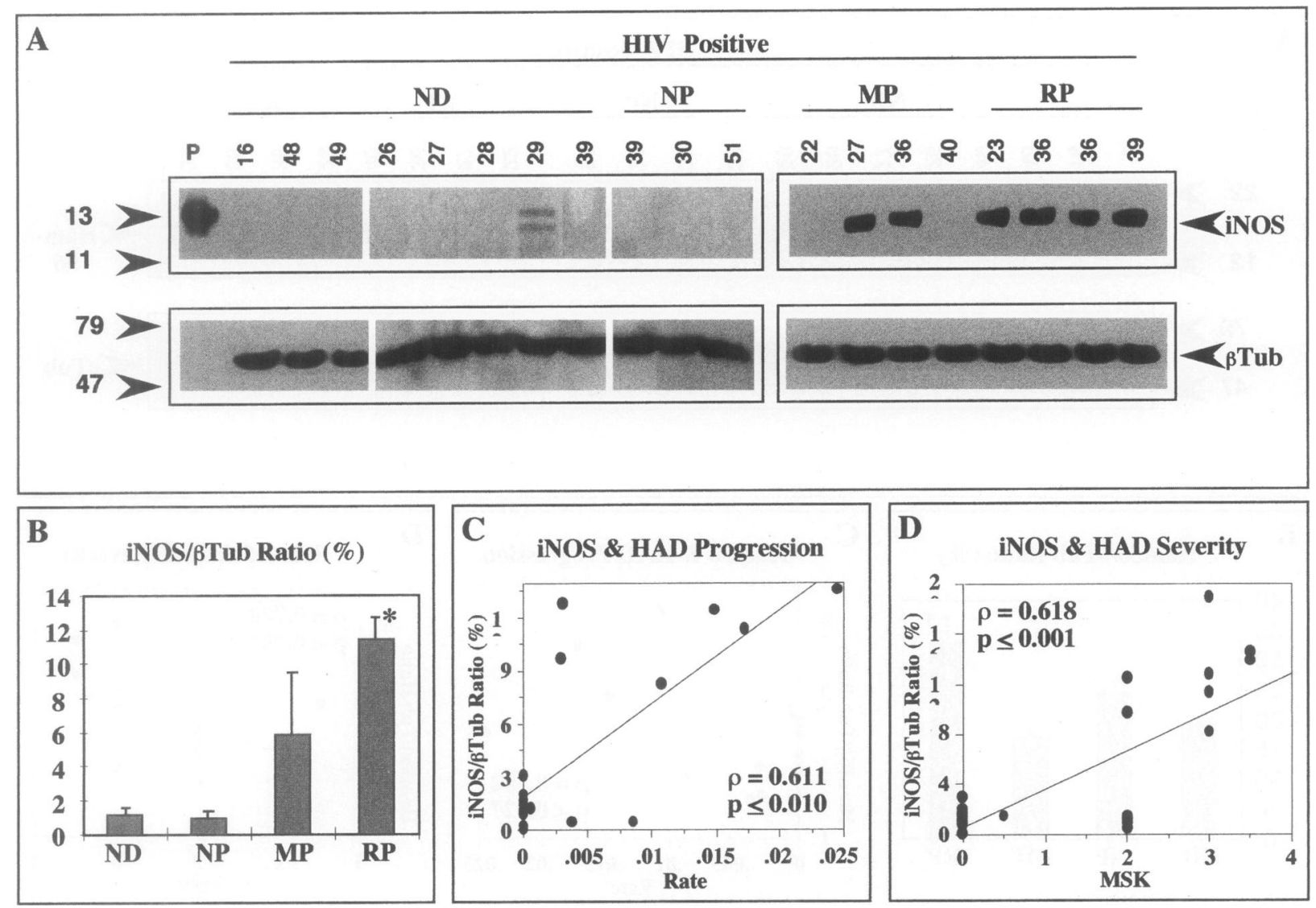

Fig. 2. Expression of iNOS protein coincides with rapid progression of HAD. (A) iNOS and $\beta$-tubulin ( $\beta$ Tub) protein immunoblots of postmortem cortical tissue from HIV-l-infected patients with no dementia (ND), non-progression (NP), moderate progression (MP), and rapid progression (RP) of HAD. These results were replicated three times with similar results. Positive controls $(\mathrm{P})$ were obtained from lipopolysaccharide-stimulated rodent glial cultures. ND and NP samples were from separate immunoblots (white space between blots) and aligned for comparison. (B) Mean levels of iNOS protein relative to that of $\beta$-tubulin from HIV-1-infected patients with ND, NP, MP, and RP. Representative

used to assess macrophage activation in postmortem tissue (5). We observed a baseline level of HAM56 expression in all samples and a significant increase in expression in the rapid progressor group (Fig. 3A, B). Correlation analysis yielded a moderate but significant positive correlation between HAM56 protein expression and HAD progression $(\rho=0.502, p \leq 0.027 ;$ Fig. $3 C)$. HAM56/ $\beta$-tubulin ratios were also compared with MSK scores; this comparison included our previous patient cohort (24). We observed a strong and significant correlation between HAM56 levels and the severity of $\operatorname{HAD}(\rho=$ $0.700, p \leq 0.001$; Fig. 3D). blots are shown in (A). The levels of iNOS were analyzed for significance by means of the Kruskal-Wallis test for multiple groups $(p \leq 0.05)$. *Fisher's leastsignificance difference posthoc test indicated highly significant differences for iNOS (RP to ND, $p \leq$ 0.0001 ; $\mathrm{RP}$ to NP, $p \leq 0.0003$; $\mathrm{RP}$ to $\mathrm{MP}, p \leq$ 0.0229). Data are means \pm SEM. (C) The Spearman rank correlation test was used to compare iNOS/ $\beta$ tubulin ratios to progression of HAD and yielded $\rho=$ $0.611, p \leq 0.010$. (D) The Spearman rank correlation test was used to compare iNOS/ $\beta$-tubulin ratios to severity of HAD and yielded $\rho=0.618, p \leq$ 0.001 . Eleven additional cases were used in the statistical analysis (24).

The HIV-1 viral proteins gp41, gpl20, and p24 levels were also examined via immunoblotting and compared with rate and severity of progression. As in previous reports $(24,41,42)$, we were unable to detect gpl20. Like iNOS and HAM56 protein expression, significantly elevated levels of gp41 protein were found in rapid progressors (Fig. 4A, B). Correlation analysis showed a significant correlation between the progression of HAD and gp4l/ $\beta$-tubulin ratios $(\rho$ $=0.564, p \leq 0.017$; Fig. $4 \mathrm{C}$ ). In the comparison of MSK scores with gp4l/ $\beta$-tubulin ratios we again combined data from this study with those from our previous patient cohort (24). We con- 

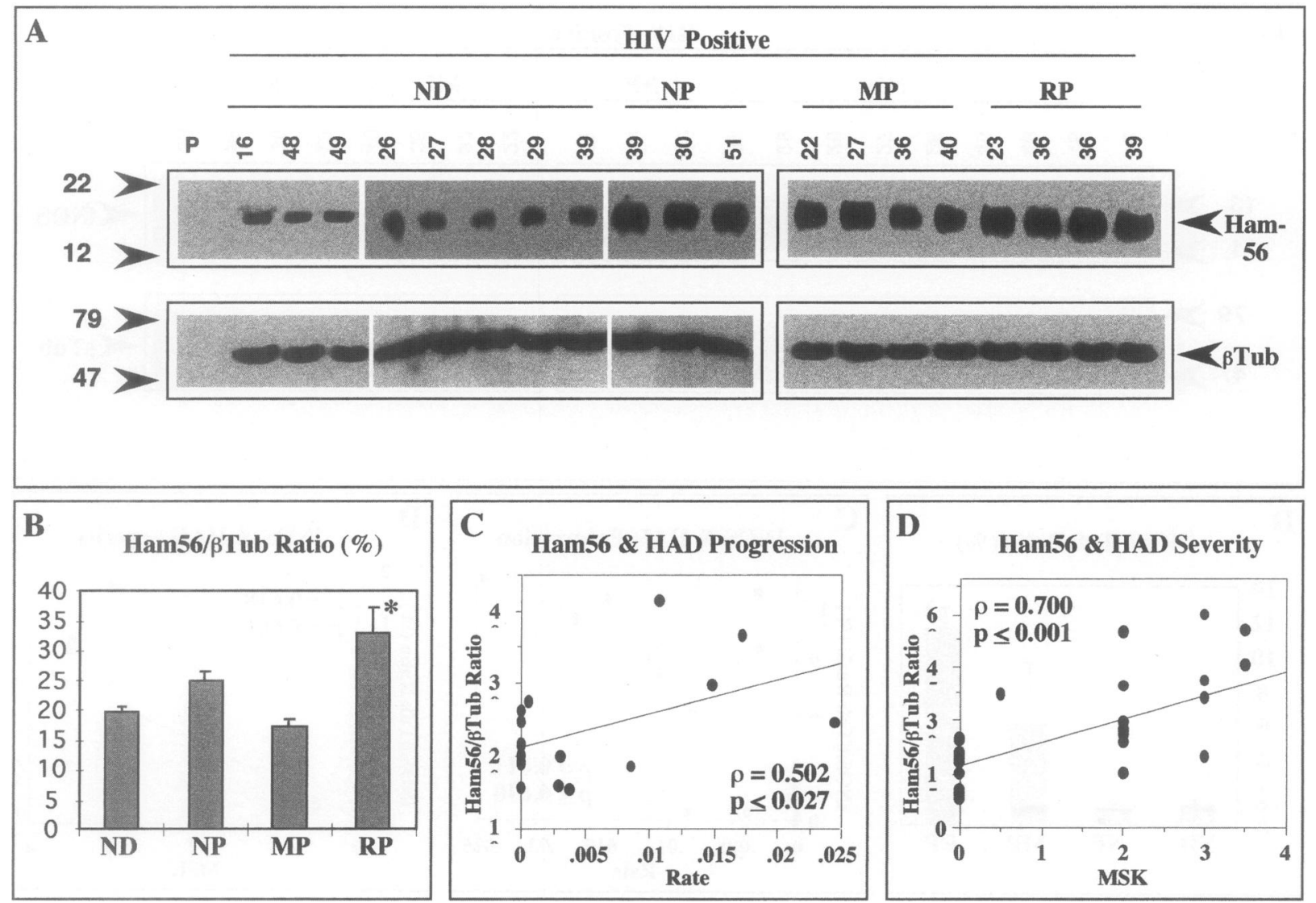

Fig. 3. Expression of HAM56 protein coincides with rapid progression of HAD. (A) HAM56 and $\beta$-tubulin ( $\beta$ Tub) protein immunoblots of postmortem cortical tissue from HIV-1-infected patients with no dementia (ND), non-progression (NP), moderate progression (MP), and rapid progression (RP) of HAD. These results were replicated three times with similar results. ND and NP samples were from separate immunoblots (white space between blots) and aligned for comparison. P, positive control. (B) Mean levels of HAM 56 protein relative to that of $\beta$-tubulin from HIV-1-infected patients with ND, NP, MP, and RP. Representative blots are shown in (A). The levels of HAM56 were analyzed for significance by

firmed and extended our prior observations that a strong and significant correlation exists between gp4l levels and MSK scores $(\rho=0.709, p$ $\leq 0.001$ ). In a comparison of p24 levels with rates of progression and MSK scores, p24 levels were not correlated with rate $(\rho=0.171, p \leq$ $0.467)$ or MSK scores $(\rho=0.284, p \leq 0.114$; Fig. 5).

\section{Discussion}

In the present study we show that the severity and rate of progression of HAD correlates signif- means of the Kruskal-Wallis test for multiple groups $(p \leq 0.006)$. *Fisher's least significance difference posthoc test indicated highly significant differences for HAM56 (RP to ND, $p \leq 0.0001$; RP to NP, $p \leq$ 0.0137 ; RP to MP, $p \leq 0.0001)$. Data are means \pm SEM. (C) The Spearman rank correlation test was used to compare HAM56/ $\beta$-tubulin ratios to progression of HAD and yielded $\rho=0.502, p \leq 0.027$. (D) The Spearman rank correlation test was used to compare HAM56/ $\beta$-tubulin ratios to severity of HAD and yielded $\rho=0.700, p \leq 0.001$. Eleven additional cases were used in the statistical analysis (data not shown).

icantly with levels of the HIV-1 coat protein, gp41, iNOS, and HAM56, a marker of microglial/ macrophage activation. Our observations extend and strengthen our previous studies in which we showed that only the severity of HAD correlated with indices of immune system activation (5) and with levels of iNOS and gp4l (24). Other investigators have observed mRNA or protein for iNOS $(24,26,43)$ in CNS tissue from HIV demented individuals. The failure of Bagasra et al. (44) to detect iNOS mRNA by in situ PCR may be due to a lack of prospective analysis and staging of HAD patients, as iNOS protein is only detectable in moderate to severely demented HIV-1 - 

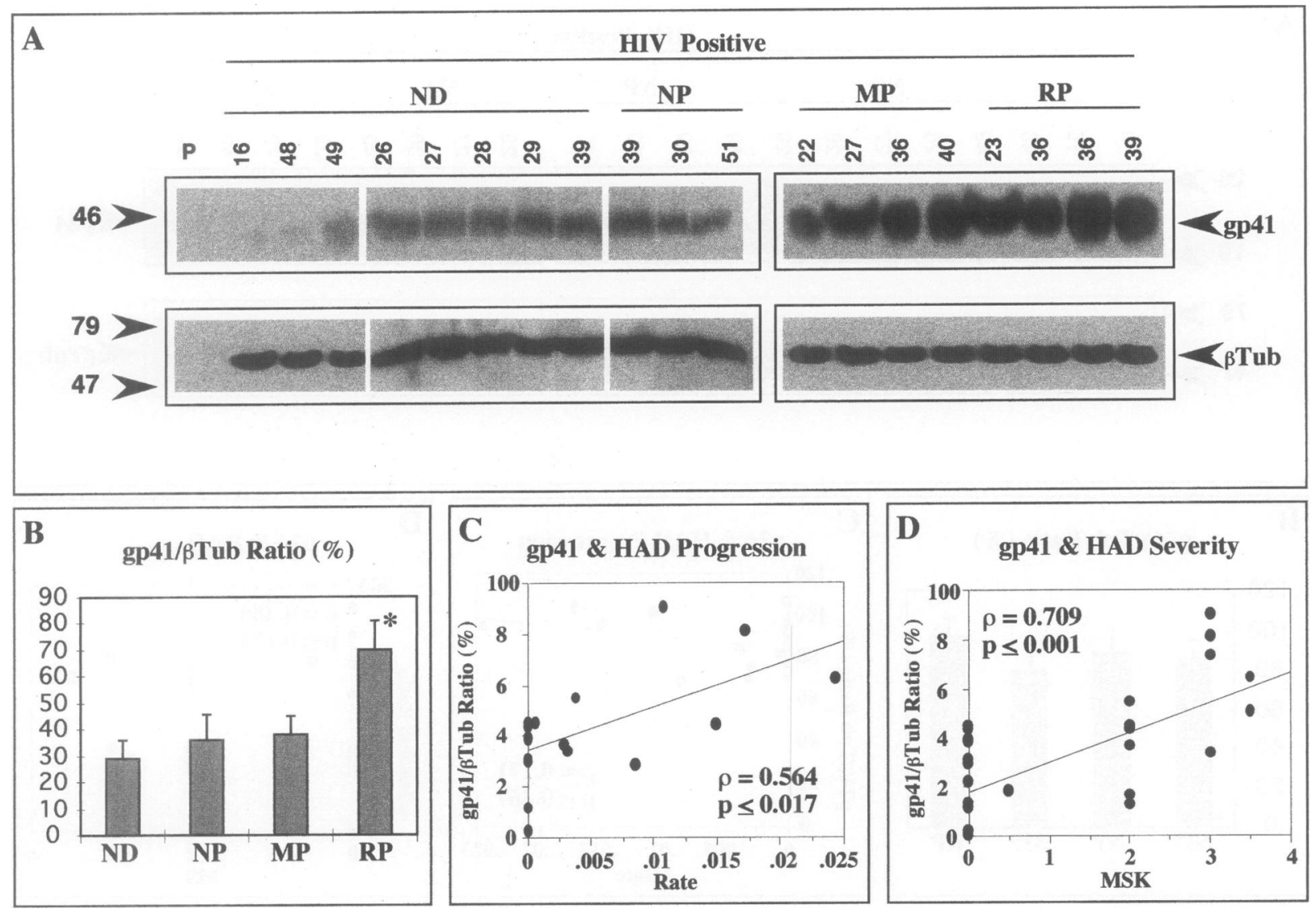

Fig. 4. Expression of HIV-1 gp41 protein coincides with rapid progression of HAD. (A) gp4l and $\beta$-tubulin ( $\beta$ Tub) protein immunoblots of postmortem cortical tissue from HIV-1-infected patients with no dementia (ND), non-progression (NP), moderate progression (MP), and rapid progression (RP) of HAD. These results were replicated three times with similar results. ND and NP samples were from separate immunoblots (white space between blots) and aligned for comparison. $\mathrm{P}$, positive control. (B) Mean levels of gp4l protein relative to that of $\beta$-tubulin from HIV-1-infected patients with ND, NP, MP, and RP. Representative blots are shown in (A). The

infected patients (24). There appears to be a threshold effect in which high levels of gp4l, iNOS, and HAM56 are particularly associated with severe (MSK 3 to 4) and rapidly progressive HAD. Thus, iNos, gp4l, and macrophage/microglial activation are the first neuropathogical variables identified that correlate with the rate of progression of $\mathrm{HAD}$. We have previously reported no statistically significant difference among these groups in the amount of brain atrophy, white matter hyperintensity, microglial nodules, multinucleated giant cells, perivascular cuffs, diffuse myelin pallor, multifocal white matter lesions, infarction, vacuolar myelopathy, levels of gp4l were analyzed for significance by means of the Kruskal-Wallis test for multiple groups $(p \leq 0.05)$. *Fisher's least-significance difference posthoc test indicated highly significant differences for iNOS (RP to ND, $p \leq 0.0020$; RP to NP, $p \leq$ 0.0082; RP to MP, $p \leq 0.0130$ ). Data are means \pm SEM. (C) The Spearman rank correlation test was used to compare gp41/ $\beta$-tubulin ratios to progression of HAD and yielded $\rho=0.564, p \leq 0.017$. (D) The Spearman rank correlation test was used to compare iNOS/ $\beta$-tubulin ratios to severity of HAD and yielded $\rho=0.709, p \leq 0.001$. Eleven additional cases were used in the statistical analysis (24).

cytomegalovirus (CMV) inclusions, or gliosis (36). Although gp4l appears to play a prominent role in the rate and severity of progression of $\mathrm{HAD}$, it is unlikely to be the sole or primary insult in HAD as a number of host and viral factors have been shown to modulate or contribute to HAD. These other factors may be particularly important in less severe cases of HAD.

Previous studies have shown a wide variability in the rates of progression of HAD among HIV-infected individuals $(2,20,36,45)$. We have previously identified unique groups within this spectrum which we designated non-, moderate, and rapid progressors (36). Non- and moderate 

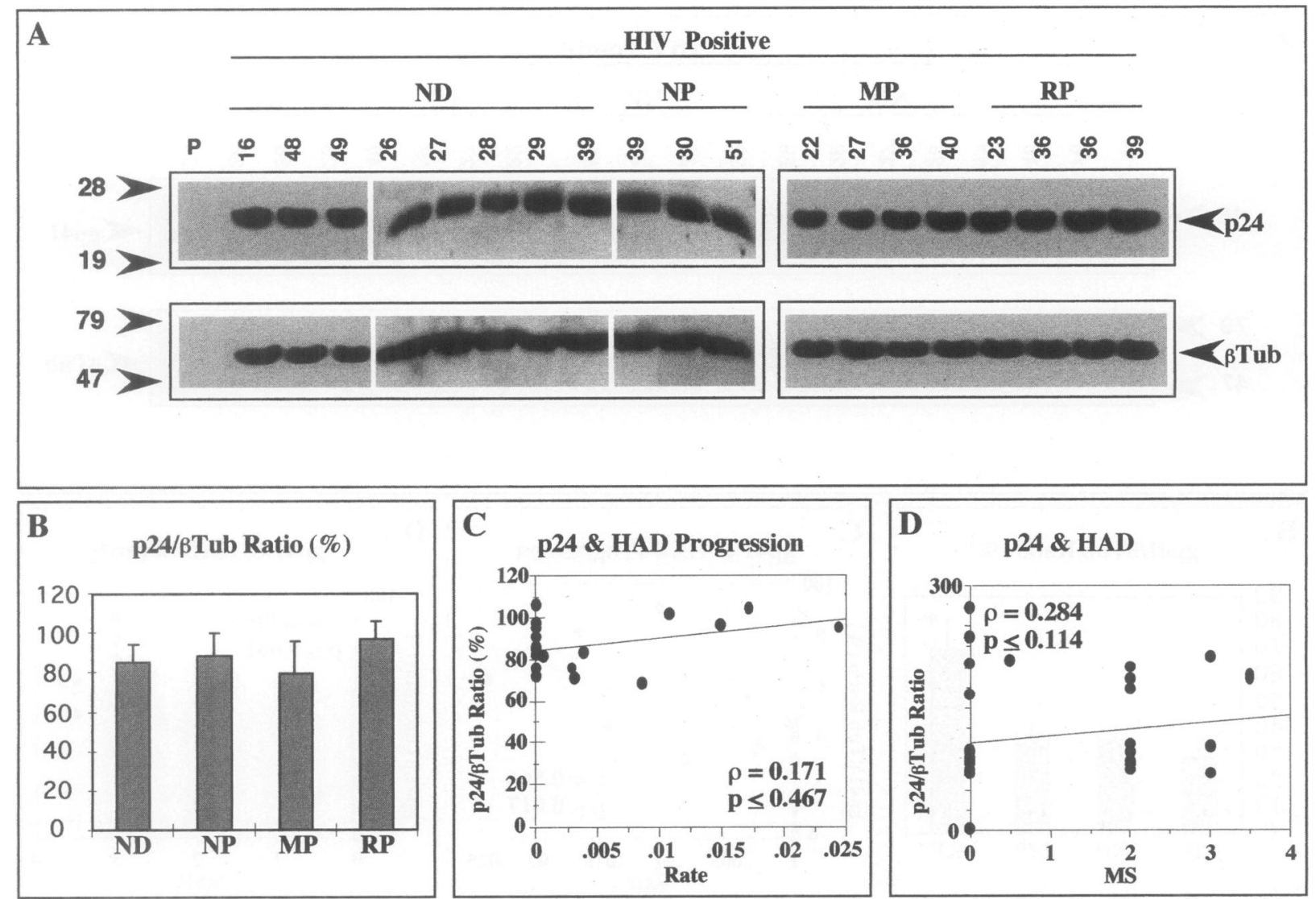

Fig. 5. Expression of HIV-1 p24 viral protein does not coincide with rapid progression of HAD. (A) p24 and $\beta$-tubulin ( $\beta$ Tub) protein immunoblots of postmortem cortical tissue from HIV-1infected patients with no dementia (ND), non-progression (NP), moderate progression (MP), and rapid progression (RP) of HAD. These results were replicated three times with similar results. Positive control $(\mathrm{P})$ was used for iNOS protein. ND and NP samples were from separate immunoblots (white space between blots) and aligned for comparison. (B) Mean levels of $\mathrm{p} 24$ protein were relative to that of $\beta$-tubulin from HIV-1-infected patients with ND, NP, $\mathrm{MP}$, and RP. Representative blots are shown in (A).

progressors have a very slow neurological progression over a course of months to years, whereas the rapid progressors show rapid increases in neurological severity over weeks to months (36). One limitation in our data is that the rate of neurological progression was determined from only two MSK scores, assuming a linear change. Such an assumption easily overlooks a stepwise or multiphasic change, e.g., an initially slow change followed by a rapid change. Prior studies have indicated that there is no difference in progression to AIDS according to sex, race, or risk factor for HIV infection $(30,45)$,
The levels of p24 were analyzed for significance by the Kruskal-Wallis test for multiple groups $(p \leq$ 0.22 ). Fisher's least-significance difference posthoc test did not indicate significant differences for $\mathrm{p} 24$ (RP to ND, $p \leq 0.13 .11$; RP to NP, $p \leq 0.3231 ; \mathrm{RP}$ to MP, $p \leq 0.0513$ ). Data are means \pm SEM. (C) The Spearman rank correlation test was used to compare $\mathrm{p} 24 / \beta$-tubulin ratios to progression of HAD and yielded $\rho=0.171, p \leq 0.467$. (D) The Spearman rank correlation test was used to compare p24/ $\beta$ tubulin ratios to severity of HAD and yielded $\rho=$ $0.284, p \leq 0.114$. Eleven additional cases were used in the statistical analysis (24).

whereas others have shown a difference according to race, risk factor, CD4 count, and survival to death (46). Since we wanted to examine potential differences in protein markers with rate of progression, we controlled for these factors by choosing groups with no difference in CD4 count and survival (Table 1). Additionally, we attempted to control for protein degradation by choosing cases with similar postmortem intervals from tissue procurement to freezing, and simultaneously preparing all the samples in an identical fashion.

The striking and statistically significant eleva- 
tion of gp $41 / \beta$-tubulin ratios in severe and rapidly progressing $\mathrm{HAD}$ and the failure to detect gp120 are puzzling. Other investigators have also failed to detect gpl 20 in the brains of HAD patients $(41,42)$. Theories on this failure suggest that gp120 is rapidly degraded by extracellular proteases, thus preventing its detection in brain. Alternatively, it has been suggested that antibodies used to detect gpl20 do not recognize gpl20 in the brain because of the specificity of the antibodies used. However, these antibodies readily detect gp120 in the periphery of HIV-infected patients by both immunohistochemical and Western blot approaches (47-49). Recently, SIV-infected macaques with neurologic disease were also found to have levels of gp4l that correlated with the extent of disease, whereas viral load failed to show any correlation (J. Clements and M. C. Zink, personal communication). Thus, it is becoming clear that there are complexities in the regulation and expression of HIV proteins, particularly gp41, that may play important roles in the pathogenesis of HAD. This dissociation between gp4l expression patterns and p24 expression patterns is puzzling. It is not likely due to cross-reactivity of the p24 or gp4l antibodies with a human protein, as we observed only a single band on immunoblot that is present only in HIV-infected patients (see Patients and Methods, ref. 24). Changes in protein expression patterns are due to either increased translation or decreased degradation. In the SIV model a single point mutation in the gp4l region of env results in a virus that causes neurologic disease and increased gp4l expression which does not directly correlate with viral message (50). It is unlikely that a single point mutation in gp4l would confer increased viral translation, although it is likely that a point mutation would alter the rate of protein degradation. Little is known about the kinetics of HIV protein expression in the CNS. In COS cell lines env expression kinetics are regulated by rev and tat and by the efficiency of proteolytic cleavage of gpl60 (51), while expression of Pr55gag inhibits internalization and degradation of gp4l (52). In the CNS where viral replication and maturation is slowed, gp41 will not be lost due to the production of viral particles, and if degradation is inhibited by expression of Pr55gag, then it is feasible that gp41 would accumulate, perhaps in relation to soluble HIV proteins that would be exposed to proteolytic processes.

In vitro studies in both rodent and human glial cultures indicate that full-length and appropriately post-translationally modified gp41 expressed on cellular membranes by vesicular stomatitis virus
(VSV) is a potent inducer of TNF- $\alpha, \mathbb{L}-1 \beta$, and iNOS $(53,54)$. Interestingly, recombinant bacterially expressed gp4l containing the extracellular domain obtains appropriate tertiary structure $(55,56)$ and behaves in an identical manner to full-length gp4l in inducing TNF- $\alpha, \mathrm{IL}-1 \beta$, and iNOS $(24,54,57)$. Thus, the elevated levels of gp41 in severe and rapidly progressing $\mathrm{HAD}$ may act as an activator of the immune system and elicit a sustained immunologic reaction that triggers pathogenic processes, ultimately leading to severe and rapid progression of HAD. Consistent with this notion is our observation that subnanomolar physiologically relevant concentrations of recombinant gp4l is neurotoxic to rodent cultures and kills neurons in an NO-dependent fashion from induction of iNOS $(24,57)$. Recent studies indicate that recombinant gp41 is also toxic to human neuronal cultures in an iNOS/NO-dependent fashion (L. Pulliam, personal communication). We propose that, like nonsecreted membrane proteins that induce signaling processes through cell-to-cell interactions, the extracellular portion of gp4l expressed in infected cells interacts with adjacent cells to cause macrophage/microglial activation and induction of iNOS. This is particularly important in the latter stages of $\mathrm{HAD}$. Strategies aimed at reducing levels of gp4l or interfering with signaling cascades induced by gp4l may have therapeutic benefit.

\section{Acknowledgments}

V. L. D. is supported by US PHS grants NS 26643. T. M. D. is an Established Investigator of the American Heart Association and is supported by and the Paul Beeson Faculty Scholar Award in Aging Research. Under an agreement between the Johns Hopkins University and Guilford Pharmaceuticals, T. M. D and V. L. D. are entitled to a share of sales royalty received by the University from Guilford. T. M. D. and the University also own Guilford stock, and the University stock is subject to certain restrictions under University policy. The terms of this arrangement are being managed by the University in accordance with its conflict-of-interest policies.

\section{References}

1. McArthur JC. (1997) NeuroAIDS: diagnosis and management. Hosp. Prac. Aug: 73-97.

2. Navia BA, Jordan BD, Price RW. (1986) The AIDS dementia complex: I. Clinical features. Ann. Neurol. 19: 517-524. 
3. Price RW, Brew B, Sidtis J, Rosenblum M, Scheck AC, Cleary P. (1988) The brain in AIDS: central nervous system HIV-1 infection and AIDS dementia complex. Science 239: 586-592.

4. Zheng J, Gendelman HE. (1997) The HIV-1 associated dementia complex: a metabolic encephalopathy fueled by viral replication in mononuclear phagocytes. Curr. Opin. Neurol. 10: 319-325.

5. Glass JD, Fedor $\mathrm{H}$, Wesselingh SL, McArthur JC. (1995) Immunocytochemical quantitation of human immunodeficiency virus in the brain: correlations with dementia. Ann. Neurol. 38: 755-762.

6. Takahashi $\mathrm{K}$, Wesselingh SL, Griffin DE, McArthur JC, Johnson RT, Glass JD. (1996) Localization of HIV-1 in human brain using polymerase chain reaction/in situ hybridization and immunocytochemistry. Ann. Neurol. 39: 705-711.

7. Koenig S, Gendelman HE, Orenstein JM, et al. (1986) Detection of AIDS virus in macrophages in brain tissue from AIDS patients with encephalopathy. Science 233: 1089-1093.

8. Dickson DW, Lee SC, Liu W, Brosnan CF. (1994) Microglial involvement in the acquired immunodeficiency syndrome (AIDS). Neuropathol. Appl. Neurobiol. 20: 211-213.

9. Tornatore C, Chandra R, Berger JR, Major EO. (1994) HIV-1 infection of subcortical astrocytes in the pediatric central nervous system. Neurology 44: 481-487.

10. Tornatore C, Meyers K, Atwood W, Conant K, Major E. (1994) Temporal patterns of human immunodeficiency virus type 1 transcripts in human fetal astrocytes. J. Virol. 68: 93-102.

11. Everall IP, Glass JD, McArthur J, Spargo E, Lantos P. (1994) Neuronal density in the superior frontal and temporal gyri does not correlate with the degree of human immunodeficiency virus-associated dementia. Acta Neuropathol. 88: 538-544.

12. Wiley CA, Masliah E, Morey M, et al. (1991) Neocortical damage during HIV infection. Ann. Neurol. 29: 651-657.

13. Masliah E, Ge N, Morey M, DeTeresa R, Terry RD, Wiley CA. (1992) Cortical dendritic pathology in human immunodeficiency virus encephalitis. $L a b$. Invest. 66: 285-291.

14. Epstein LG, Gendelman HE. (1993) Human immunodeficiency virus type 1 infection of the nervous system: pathogenetic mechanisms. Ann. Neurol. 33: 429-436.

15. Lipton SA, Gendelman HE. (1995) Dementia associated with the acquired immunodeficiency syndrome. Seminars in medicine of the Beth Israel Hospital, Boston. N. Engl. J. Med. 332: 934-940.

16. Teo I, Veryard C, Barnes H, et al. (1997) Circular forms of unintegrated human immunodeficiency virus type 1 DNA and high levels of viral protein expression: association with dementia and multinucleated giant cells in the brains of patients with AIDS. J. Virol. 71: 2928-2933.

17. Pulliam L, Gascon R, Stubblebine M, McGuire D,
McGrath MS. (1997) Unique monocyte subset in patients with AIDS dementia. Lancet 349: 692695.

18. Brew BJ, Dunbar N, Penberton, Kaldor J. (1996) Predictive markers of AIDS dementia complex: CD4 count and cerebrospinal fluid concentrations of beta 2-microglobulin and neopterin. J. Infect. Dis. 174: 294-298.

19. Sacktor NC, Bacellar H, Hoover DR, et al. (1996) Psychomotor slowing in HIV infection: predictor of dementia, AIDS and death. J. Neurovirol. 2: 404-410.

20. Wiley CA, Achim CL. (1994) Human immunodeficiency virus encephalitis is the pathological correlate of dementia in acquired immunodeficiency syndrome. Ann. Neurol. 36: 673-676.

21. Brew BJ. (1996) Human immunodeficiency virus in brain and correlation with dementia. Ann. Neurol. 39: 828-829.

22. Pang S, Koyanagi $Y$, Miles S, Wiley C, Vinters HV, Chen IS. (1990) High levels of unintegrated HIV-1 DNA in brain tissue of AIDSdementia patients. Nature 343: 85-89.

23. Brew BJ, Pemberton L, Cunningham P, Law MG. (1997) Levels of human immunodeficiency virus type 1 RNA in cerebrospinal fluid correlate with AIDS dementia stage. J. Infect. Dis. 175: 963-966.

24. Adamson DC, Wildermann B, Sasaki M, et al. (1996) Immunologic NO synthase: elevation in severe AIDS dementia and induction by HIV-1 gp4l Science 274: 1917-1921.

25. Wiley CA, Nelson JA. (1990) Human immunodeficiency virus: infection of the nervous system. Curr. Top. Microbiol. Immunol. 160: 157-172.

26. Nuovo GJ, Alfieri ML. (1996) AIDS dementia is associated with massive, activated HIV-1 infection and concomitant expression of several cytokines. Mol. Med. 2: 358-366.

27. Chaisson RE, Keruly JC, Moore RD. (1995) Race, sex, drug use, and progression of human immunodeficiency virus disease. $N$. Engl. J. Med. 333: 751-756.

28. Operskalski EA, Stram DO, Lee H, et al. (1995) Human immunodeficiency virus type 1 infection: relationship of risk group and age to rate of progression to AIDS. J. Infect. Dis. 172: 648-655.

29. Saah AJ, Munoz A, Kuo V, et al. (1992) Predictors of risk of development of acquired immunodeficiency syndrome within 24 months among gay men seropositive for human immunodeficiency virus type 1: a report from the Multicenter Center AIDS Cohort Study. Am. J. Epidemiol. 135: 11471155.

30. Von Overbeck J, Egger M, Smith GD, et al. (1994) Survival in HIV infection: do sex and category of transmission matter? Swiss HIV Cohort Study. AIDS 8: 1307-1313.

31. Cunningham AL, Naif H, Saksena N, et al. (1997) HIV infection of macrophages and pathogenesis of AIDS dementia complex: interaction of the host 
cell and viral genotype. J. Leukoc. Biol. 62: 117125.

32. Navia BA, Jordon BD, Price RW. (1986) The AIDS dementia complex: I. Clinical features. Ann. Neurol. 19: 517-524.

33. McArthur JC. (1987) Neurologic manifestations of AIDS. Medicine 66: 407-437.

34. Portegies P, Enting RH, de Gans J, et al. (1993) Presentation and course of AIDS dementia complex: ten years of follow-up in Amsterdam, The Netherlands. AIDS 7: 669-675.

35. Tozzi V, Narciso P, Galgani S, et al. (1993) Effects of zidovudine in 30 patients with mild to endstage AIDS dementia complex. AIDS 7: 683-692.

36. Bouwman FH, Skolasky R, Hes D, et al. (1998) Variable progression of HIV-associated dementia. Neurology 50: 1814-1820.

37. Janssen RS, Cornblath DR, Epstein LG, McArthur J, Price RW. (1991) Nomenclature and research case definitions for neurological manifestations of human immunodeficiency virus type-1 (HIV-1) infection. Report of a Working Group of the American Academy of Neurology AIDS Task Force. Neurology 41: 778-785.

38. Price RW, Brew BJ. (1988) The AIDS dementia complex. J. Infect. Dis. 158: 1079-1083.

39. Folstein MF, Folstein SE, McHugh PR. (1975) Mini-Mental State: a practical method for grading the cognitive state of patients for the clinician. J. Psychiatr. Res. 12: 189-198.

40. Power C, McArthur JC, Johnson RT, et al. (1994) Demented and non-demented patients with AIDS differ in brain-derived human immunodeficiency virus type 1 envelope sequences. J. Virol. 68: 4643-4649.

41. Toggas SM, Masliah E, Rockenstein EM, Rall GF, Abraham CR, Mucke L. (1994) Central nervous system damage produced by expression of the HIV-1 coat protein gp 120 in transgenic mice. $\mathrm{Na}$ ture 367: 188-193.

42. Hill JM, Mervis RF, Avidor R, Moody TW, Brenneman DE. (1993) HIV envelope protein-induced neuronal damage and retardation of behavioral development in rat neonates. Brain Res. 603: 222-233.

43. Bukrinsky MI, Nottet HS, Schmidtmayerova H, et al. (1995) Regulation of nitric oxide synthase activity in human immunodeficiency virus type 1 (HIV-1)-infected monocytes: implications for HIVassociated neurological disease. J. Exp. Med. 181: 735-745.

44. Bagasra O, Bobroski L, Sarker A, Bagasra A, Saikumari P, Pomerantz RJ. (1997) Absence of the inducible from of nitric oxide synthase in the brains of patients with the acquired immunodeficiency syndrome. J. Neurovirol. 3: 153-167.

45. Portegies P. (1995) The Neurology of HIV-1 Infection. MediTech Media, London.

46. Levy JA. (1993) The transmission of HIV and factors influencing progression to AIDS. Am. J. Med. 95: 86-100.
47. Galli RA, Castriciano S, Fearon M, Major C, Choi KW, Mahony J, Chernesky M. (1996) Performance characteristics of recombinant enzyme immunoassay to detect antibodies to human immunodeficiency virus type 1 (HIV-1) and HIV-2 and to measure early antibody responses in seroconverting patients. J. Clin. Microbiol. 34: 999-1002.

48. Pudney J, Anderson D. (1995) Effects of fixation and paraffin embedding on the immunohistological detection of cell-associated HIV-1 by different monoclonal antibodies. J. Histochem. Cytochem. 43: 857-862.

49. Portincasa $P$, Conti G, Zannino T, Visalli S, Chezzi C. (1994) Radioimmune western blotting in comparison with conventionalwestern blotting, second and third generation ELISA assays for the serodiagnosis of HIV-1 infection. New Microbiol. 17: 169-176.

50. Flaherty MT, Hauer DA, Mankowski JL, Zink MC, Clements JE. (1997) Molecular and biological characterization of a neurovirulent molecular clone of simian immunodeficiency virus. J. Virol. 71: $5790-5798$.

51. Bird C, Burke J, Gleeson PA, McCluskey J. (1990) Expression of human immunodeficiency virus 1 (HIV-1) envelope gene products transcribed from a heterologous promoter. Kinetics of HIV-1 envelope processing in transfected cells. J. Biol. Chem. 265: 19151-19157.

52. Egan MA, Carruth LM, Rowell JF, Yu X, Siliciano RF. (1996) Human immunodeficiency virus type 1 envelope protein endocytosis mediated by a highly conserved intrinsic internalization signal in the cytoplasmic domain of gp4l is suppressed in the presence of the Pr55gag precursor protein. J. Virol. 70: 6547-6556.

53. Koka P, He K, Camerini D, Tran T, Yashar SS, Merrill JE. (1995) The mapping of HIV-1 gpl60 epitopes required for interleukin-1 and tumor necrosis factor alpha production in glial cells. J. Neuroimmunol. 57: 179-191.

54. Koka P, He K, Zack JA, et al. (1995) Human immunodeficiency virus 1 envelope proteins induce interleukin 1, tumor necrosis factor alpha, and nitric oxide in glial cultures derived from fetal, neonatal, and adult human brain. J. Exp. Med. 182: 941-951.

55. Rabenstein MD, Shin YK. (1995) HIV-1 gp4l tertiary structure studied by EPR spectroscopy. Biochemistry 35: 13922-13928.

56. Wingfield PT, Stahl SJ, Kaufman J, et al. (1997) The extracellular domain of immunodeficiency virus gp4l protein: expression in Escherichia coli, purification, and crystallization. Protein Sci. 6: 1653-1660.

57. Adamson, DC, Kopnisky KL, Dawson TM, Dawson VL. (1999) Mechanisms and structural determinants of HIV-1 coat protein, gp4l-induced neurotoxicity. J. Neurosci. 19: 64-71. 